\title{
Sistem Informasi Keuangan dan Penjualan pada Nyonya Ngebul Vape Store
}

\author{
Dhio Saputra \\ ${ }^{1}$ Universitas Putra Indonesia YPTK Padang, Indonesia \\ dhio saputra@upiyptk.ac.id
}

\begin{abstract}
ABSTRAK
Nyonya Ngebul merupakan salah satu toko vape yang pertama berdiri di kota Padang dan lumayan besar karena sudah memiliki beberapa cabang toko. Namun pada kegiatan jual belinya Nyonya Ngebul Vape Store masih menggunakan sistem manual, sehingga sering terjadi kesalahan yang merugikan pada saat transaksi dengan pelanggan. Dan juga pelayanan yang diberikan kepada pelanggan dirasa kurang maksimal dan kurang efisien waktu terutama di bidang pencatatan hasil transaksi. Sistem terkomputerisasi merupakan salah media yang dapat menangani permasalahan yang terjadi di Nyonya Ngebul tersebut. Pemanfaatan teknologi yang dibuat dalam sistem ini menggunakan bahasa pemrograman Java dan menggunakan MySQL sebagai manajemen basis data. Sistem yang dibuat ditujukan untuk memudahkan proses pengelolaan data yang dilakukan oleh administrator. Hasil yang diharapkan dari pembuatan sistem ini selain mengintegrasikan sistem manual ke sistem terkomputerisasi dapat juga menghasilkan output laporan keuangan dengan menggunakan teknologi Jasper Report.
\end{abstract}

Kata kunci : Nyonya Ngebul, Sistem Terkomputerisasi, Sistem Manual, Pencatatan transaksi.

\section{Pendahuluan}

Tingginya angka perokok aktif di beberapa negara berkembang termasuk Indonesia membuat perkembangan vape atau rokok elektrik semakin pesat sebagai solusi untuk berhenti menghisap rokok konvensional. Vape atau rokok elektrik adalah salah satu jenis dari penghantar nikotin elektronik. Rokok jenis ini dirancang untuk membantu pecandu rokok tembakau mulai berhenti merokok. Dengan beralih dari rokok tembakau ke rokok elektrik, secara perlahan mereka belajar untuk berhenti merokok.

Seiring dengan perkembangan zaman, vape mulai diminati oleh banyak kalangan. Hal ini lah yang mendorong berdirinya toko-toko vape yang menyediakan barang dan peralatan untuk kebutuhan vape itu sendiri. Nyonya Ngebul Vape Store adalah salah satu usaha yang menyediakan barang dan peralatan untuk vape dikota Padang.

Nyonya Ngebul Vape Store berdiri sudah cukup lama, dan merupakan salah satu toko vape yang pertama berdiri di kota Padang dan lumayan besar karena sudah memiliki beberapa cabang toko. Namun pada kegiatan jual belinya Nyonya Ngebul Vape Store masih menggunakan sistem manual, sehingga sering terjadi kesalahan yang merugikan pada saat transaksi dengan pelanggan. Dan juga pelayanan yang diberikan kepada pelanggan dirasa kurang maksimal dan kurang efisien waktu terutama di bidang pencatatan hasil transaksi.

Oleh karena itu diperlukan adanya suatu sistem informasi penjualan barang yang di harapkan mampu mengatasi kesalahan-kesalahan yang sering terjadi pada saat transaksi. Dan

Diterima Redaksi : 10-9-2020 | Selesai Revisi : 10-10-2020 | Diterbitkan Online : 11-10-2020 
juga di harapkan dapat memenuhi kebutuhan pelanggan dengan memberi pelayanan terbaik terhadap pelanggan dan meningkatkan efisiensi waktu.

\section{Tinjauan Literatur}

\subsection{Konsep Dasar Sistem Informasi}

Sistem informasi adalah suatu sistem di dalam suatu organisasi yang mempertemukan kebutuhan pengolahan transaksi harian, mendukung operasi, bersifat manajerial dan kegiatan strategi dari suatu organisasi dan menyediakan pihak luar tertentu dengan laporan-laporan yang diperlukan[1].

\subsection{Website}

Website adalah keseluruhan halaman-halaman web yang terdapat dalam sebuah domain yang mengandung informasi[2]. Sebuah website biasanya dibangun atas banyak halaman web yang saling berhubungan. Hubungan antara satu halaman web dengan halaman web lainnya disebut hyperlink sedangkan teks yang dijadikan media penghubung disebut hypertext. Website pada dasarnya disusun dengan serangkaian kodifikasi HTML dan diakses melalui protocol HTTP.

\subsection{UML}

UML (Unified Modeling Language) merupakan bahasa spesifikasi standar yang dipergunakan untuk mendokumentasikan, menspesifikasikan dan membanngun perangkat lunak. UML merupakan metodologi dalam mengembangkan sistem berorientasi objek dan juga merupakan alat untuk mendukung pengembangan sistem[3].

\subsection{MySQL}

MySQL merupakan sistem manajemen basis data yang bersifat relational. Artinya data-data yang dikelola dalam database akan diletakkan pada beberapa tabel yang terpisah sehingga manipulasi data akan menjadi jauh lebih cepat[4]. MySQL menggunakan SQL (Structure Query Language) yaitu bahasa query yang menjadi standar sistem basis data diseluruh dunia yang terbagi atas dua bagian yaitu Data Definition Language (DDL) dan Data Manipulation Language (DML).

\subsection{Java}

Java merupakan bahasa pemrograman yang multiplatform dan multi device yang dapat dijalankan di berbagai komputer maupun telepon genggam. Java pertama kali diluncurkan pada tahun 1995 sebagai bahasa pemrograman umum dengan kelebihan dia bisa dijalankan di web browser sebagai applet. Sejak awal, para pembuat Java telah menanamkan visi mereka kedalam Java untuk membuat piranti-piranti yang ada di rumah (small embedded customer device) seperti $\mathrm{TV}$, telepon, radio, dan sebagainya supaya dapat berkomunikasi satu sama lain. Tentu saja jalan menuju visi ini tidak mudah untuk ditemukan apalagi untuk ditempuh. Langkah pertama yang diambil oleh Sun Microsystem adalah dengan membuat JVM (Java Virtual Machine) yang

Diterima Redaksi : 10-9-2020 | Selesai Revisi : 10-10-2020 | Diterbitkan Online : 11-10-2020 
kemudian diimplementasikan dalam bentuk JRE (JavaRuntime Environment). JVM adalah lingkungan tempat eksekusi program Java berlangsung dimana para objek saling berinteraksi satu dengan yang lainnya. Virtual Machine inilah yang menyebabkan Java mempunyai kemampuan penanganan memori yang lebih baik, keamanan yang lebih tinggi serta portabilitas yang besar[5].

\section{Metodologi}

Ada tiga metode yang digunakan untuk mendapatkan data pada penelitian yaitu :

1. Penelitan Lapangan (Field Research)

Penelitian lapangan yaitu penelitian yang dilakukan langsung pada objek penelitian untuk mendapatkan data primer dengan teknik pengumpulan data sebagai berikut:

a. Wawancara (Interview)

Wawancara dilakukan langsung dengan Manajer Nyonya Ngebul Vape Store yang bernama Riza Azmar.

b. Pengamatan (Obsevasi)

Yaitu melakukan penelitian dan pengamatan langsung ke Nyonya Ngebul Vape Store.

c. Dokumentasi

Yaitu dengan melakukan pengambilan foto di Nyonya Ngebul Vape Store bersama manajer dari Nyonya Ngebul Vape Store.

2. Penelitian Kepustakaan (Library Research)

Penelitian kepustakaan yaitu penelitian yang dilakukan langsung pada objek penelitian untuk mendapatkan data sekunder. Dalam metode ini dilakukan dengan membaca bukubuku, literatur-literatur, diktat kuliah, Jurnal-jurnal dan artikel-artikel yang berasal dari internet yang ada kaitannya dengan penelitian.

3. Penelitian Laboratorium (Laboratory Research)

Metode ini dilakukan untuk menguji konsep-konsep yang ada dengan menggunakan personal komputer yang spesifikasi software dan hardware yang digunakan dalam penelitian ini adalah sebagai berikut:

Tabel 1. Spesifikasi Software dan Hardware

Hardware Software

$\begin{array}{ll}\text { 1. Laptop HP 14-cm0078au } & \text { 1. Sistem Operasi Windows 10 } \\ \text { 2. Memory 4 GB } & \text { 2. Microsoft Word } 2016 \\ \text { 3. Processor Intel AMD ryzen 5 } & \text { 3. Database Mysql } \\ \text { 4. Hardisk 1 TB } & \text { 4. Netbeans } \\ \text { 5. Printer Merk Canon IP2770 } & \text { 5. Xampp } \\ \text { 6. Flashdisk 16 GB } & \text { 6. Pendukung lainnya }\end{array}$

\section{Hasil dan Diskusi}

Diterima Redaksi : 10-9-2020 | Selesai Revisi : 10-10-2020 | Diterbitkan Online : 11-10-2020 
1. Desain

Desain yang digunakan Sistem Informasi Keuangan dan Penjualan pada Nyonya Ngebul Vape Store yaitu UML. Aktor-aktor yang terlibat adalah admin dan pimpinan. Berikut ini Use Case Diagram sistem tersebut yang dapat dilihat pada Gambar 1 sebagai berikut:

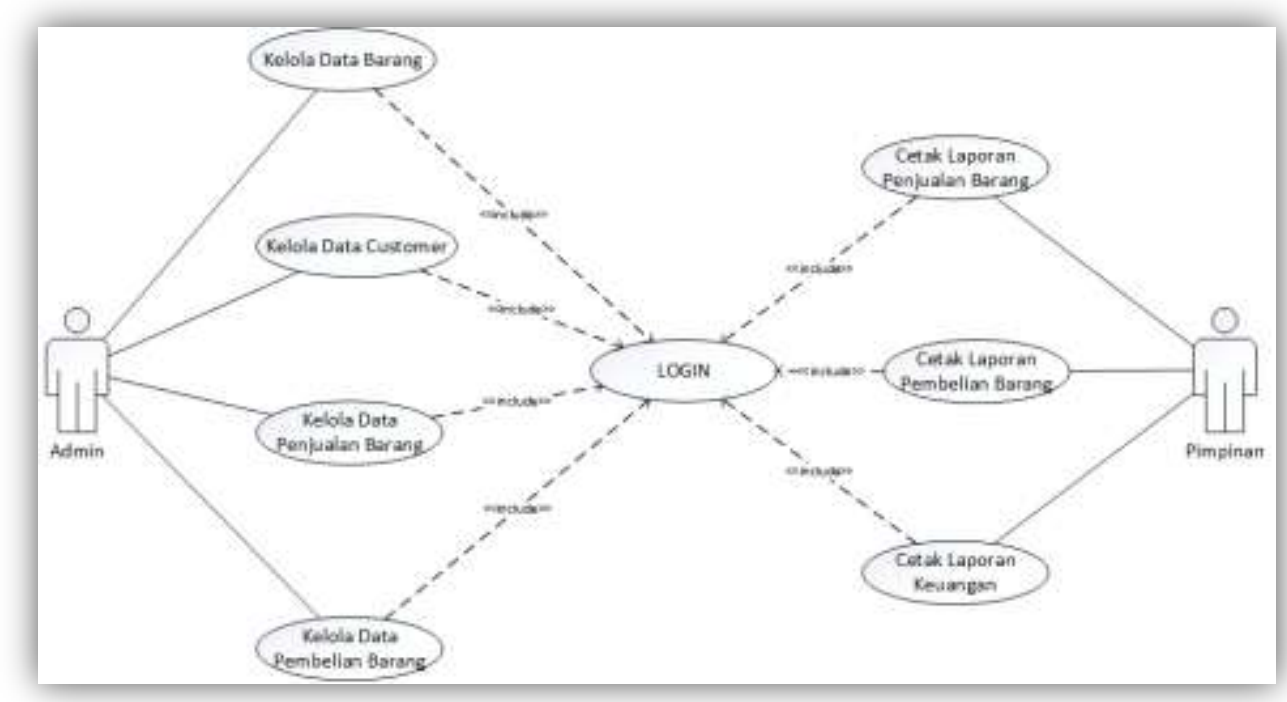

Gambar 1: Use Case Diagram

Berikut ini merupakan class diagram sistem yang dibuat pada gambar 2

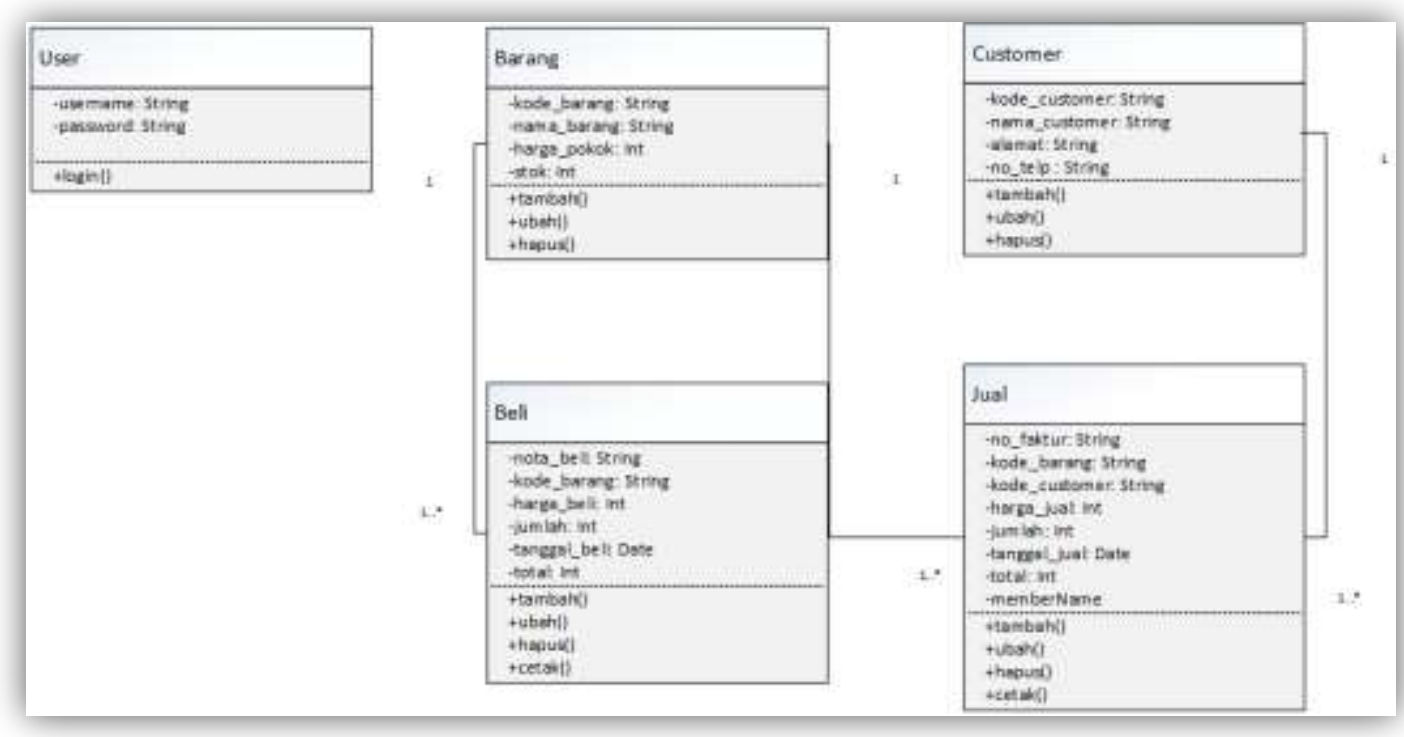

Gambar 2: Class Diagram

2. Pengembangan

Diterima Redaksi : 10-9-2020 | Selesai Revisi : 10-10-2020 | Diterbitkan Online : 11-10-2020 
Dalam merancang dan membangun sistem dibutuhkan beberapa perangkat lunak. Adapun spesifikasi perangkat lunak yang digunakan dalam pembuatan sistem:

- Operating System

- DBMS

- Tools

- Server

- Design Tool

- $\quad$ Text Editor

- Programming Language
: Windows 10 Home Single Language 64 bit

: MySQL

: XAMPP 3.2.2

: Glassfish

: Balsamic Mockups

: Netbeans

: Java

\section{Pengujian}

Pada pengujian ini, admin memiliki fungsi untuk mengelola data customer, data barang, data pembelian barang dan data penjualan barang. Berikut pada Gambar 3 merupakan tampilan menu utama admin.

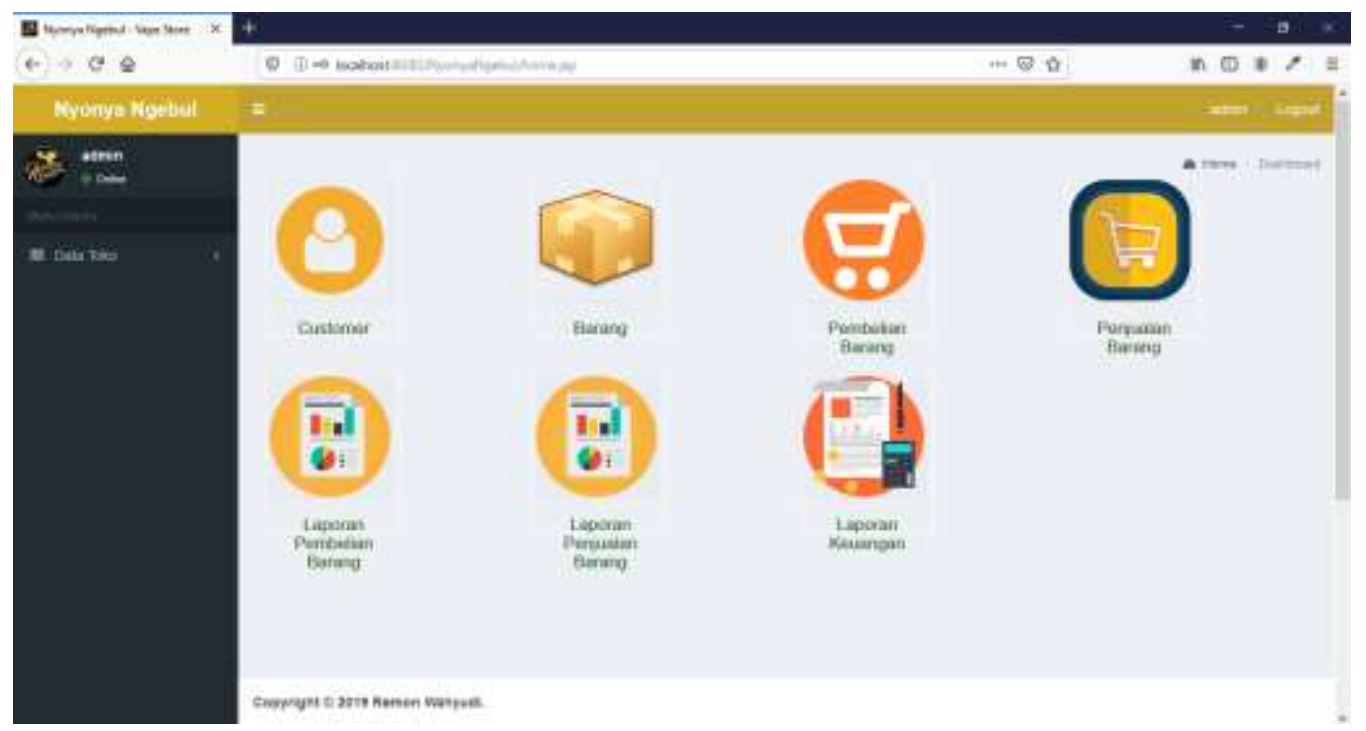

Gambar 3: Tampilan Halaman Utama Admin

4. Implementasi dan hasil

Langkah selanjutnya yaitu implementasi sistem menggunakan data aktual. Berikut ini Gambar 4 yang merupakan tampilan laporan keuangan 


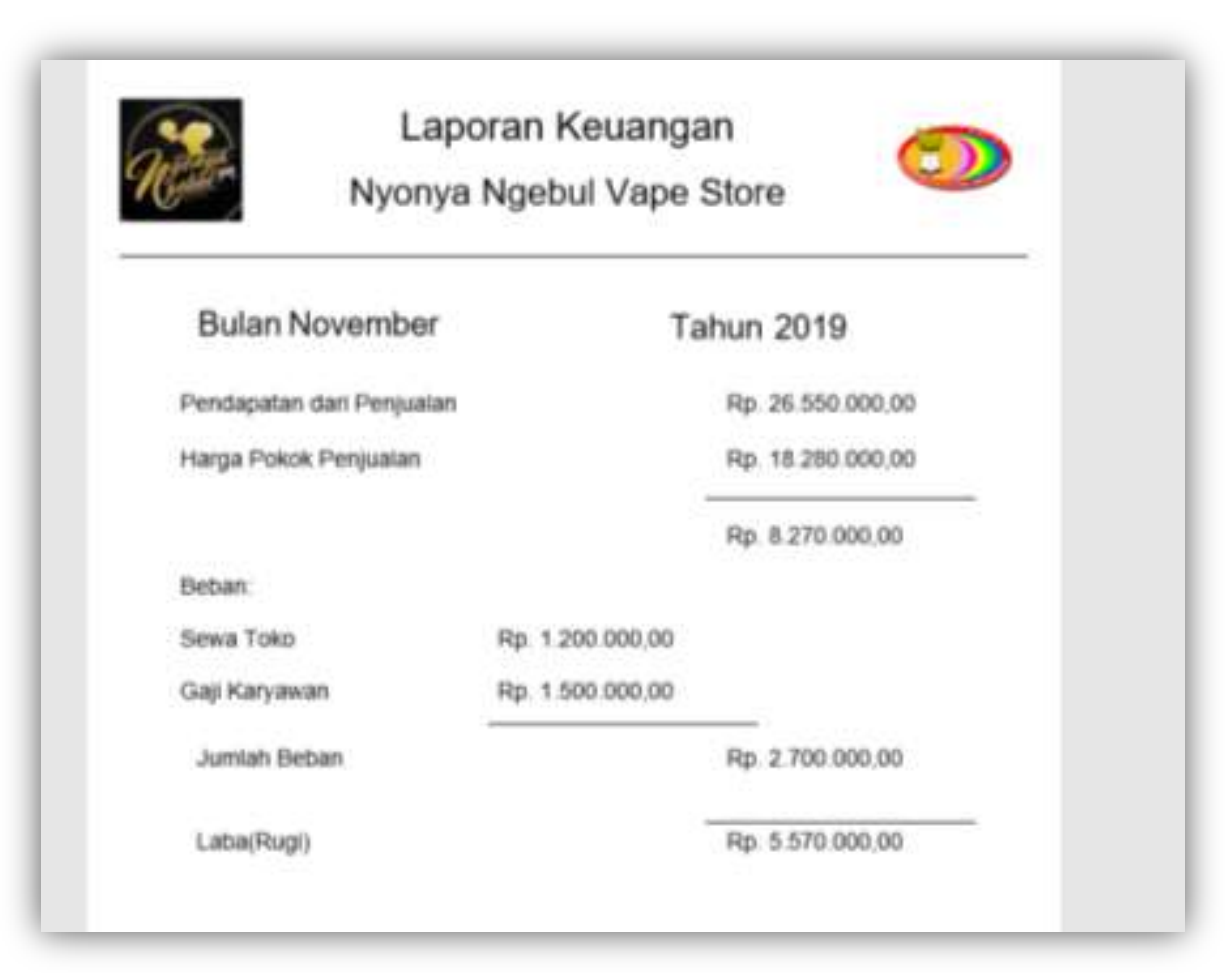

Gambar 4: Laporan Keuangan

\section{Kesimpulan}

Sistem Informasi Keuangan dan Penjualan pada Nyonya Ngebul Vape Store ditujukan untuk mempermudah administrator dalam pengelolaan data barang, pembelian serta penjualan barang yang terkomputerisasi. Perancangan aplikasi ini menggunakan bahasa pemrograman Java dan database MySQL karena dapat digunakan untuk membangun sistem dan memudahkan dalam menampilkan informasi tentang data-data toko. Sistem Informasi Informasi Keuangan dan Penjualan pada Nyonya Ngebul Vape Store yang telah dibuat merupakan implementasi dari sistem yang dimana masih menggunakan cara manual.

\section{Referensi}

[1] Jogiyanto. HM. 2005. Sistem Teknologi Informasi. ANDI. Yogyakarta.

[2] Yuhefizar. 2006. Cara Mudah Membangun Website Interaktif Menggunakan Content Management Sistem. Gramedia. Jakarta.

[3] Gata, Windu. 2013. Sukses Membangun Aplikasi Penjualan Dengan Java. Elex Media Komputindo.

[4] R.H. Sianipar. 2018. Dasar Analisis \& Perancangan Pemrograman Beorientasi Objek Menggunakan Java. Penerbit Andi, Yogyakarta.

[5] Raharjo,Budi .2011. Belajar Otodidak membuat database menggunakan MySQL. Bandung: Informatika 